\title{
Growth Characteristics of Plasma Electrolytic Oxidation Coatings on Aluminum Alloys
}

\author{
A. AydaY*, M. Durman \\ Sakarya University, Faculty of Engineering, Department of Metallurgical and Materials Engineering, \\ Sakarya 54187, Turkey
}

\begin{abstract}
The ceramic coating on aluminum alloy was prepared in sodium metasilicate electrolyte by plasma electrolytic oxidation (PEO). The effect of PEO treating time on surface layer was investigated. The morphology and phase composition of the ceramic coatings were characterized by scanning electron microscopy (SEM) and X-ray diffractometer (XRD). The effect of the electrolyte contents on the growth mechanism, element distribution and properties of oxide layers were studied. Oxide coatings morphology is strongly dependent on PEO process time. The microdischarges characteristics were studied as well, and it is shown that size of microdischarges becomes larger with increasing time of PEO. XRD analysis showed that Plasma Electrolytic Oxidation coating has hard, dominantly $\mathrm{Al}_{2} \mathrm{O}_{3}$ phase.
\end{abstract}

DOI: $10.12693 /$ APhysPolA.127.886

PACS: 78.68.+m, 81.65.-b, 52.77.-j

\section{Introduction}

Plasma electrolytic oxidation (PEO), also called micro arc oxidation (MAO) or anodic spark deposition (ASD), is an economic, efficient, and environmentally benign technology capable of producing a stable oxide coating on the surface of lightweight metals (aluminum, magnesium, zirconium, titanium, etc.). The wear resistant, corrosion resistant, electrical insulation on surface of metals can be effectively increased using PEO [1-4].

Many parameters such as current density, voltage, electrolyte additives, treatment time cause the difference in the PEO process characteristics such as breakdown voltage and final voltage. Thus the properties of the PEO coating e.g. thickness, roughness, porosity, phase composition, hardness and mechanical resistance are changed $[4,5]$.

Many researches have investigated the performance evaluation, characterization and testing aspects of PEO coatings. Therefore, the present paper describes PEO process of aluminum alloy in sodium metasilicate. The surface morphology and composition of ceramic coatings treated for different time periods were characterized by scanning electron microscopy (SEM) and x-ray diffraction (XRD). The discharge occurring on the sample surface was also recorded by a camera.

\section{Experimental}

Cylindrical samples with the dimensions of $8 \mathrm{~mm}$ (diameter) $\times 50 \mathrm{~mm}$ (height) of $\mathrm{Al}$ alloy were used as the substrate. The composition of this alloy is $0.25 \% \mathrm{Cr}$,

\footnotetext{
*corresponding author; e-mail: aayday@sakarya.edu.tr
}

$0.10 \% \mathrm{Cu}, 0.55 \% \mathrm{Mg}, 0.10 \% \mathrm{Mn}, 0.35 \% \mathrm{Fe}, 0.25 \% \mathrm{Si}$ $0.10 \% \mathrm{Ti}$, balance $\% \mathrm{Al}$. The samples were coated for 2, 10, $60 \mathrm{~min}$ by applying $20 \mathrm{~A} / \mathrm{dm}^{2}$ current density, $430 \mathrm{~V}$ and $10 \mathrm{~g} / 1 \mathrm{Na}_{2} \mathrm{SiO}_{3}$ as electrolyte. Stirring and cooling systems maintained the temperature of electrolyte at $35 \pm 5{ }^{\circ} \mathrm{C}$ during the process.

The surface morphologies of the coated samples were observed by scanning electron microscopy (SEM Joel, JSM 6060-LU). The phase composition of the coated samples was analyzed by using X-ray diffraction (600 Rigaku X-Ray Diffraction D/MAX/2200) with a $\mathrm{Cu} \mathrm{K} \alpha$ source. The uncoated and coated aluminium were measured using a FUTURE TECH-CORP.FM-700 microhardness tester at a load of $50 \mathrm{~g}$ and for a loading duration of $10 \mathrm{~s}$.

\section{Results and discussion}

Figure 1 shows microdischarges appearance at various stages of coating formation process. The size and color of microdischarge events are changing throughout the oxi-
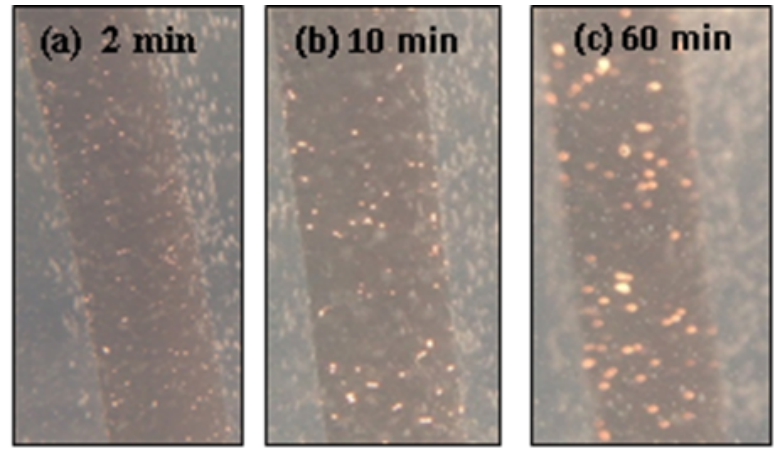

Fig. 1. Microdischarges appearance at several steps of PEO process: (a) $2 \mathrm{~min}$; (b) $10 \mathrm{~min}$; (c) $60 \mathrm{~min}$. 
dation process. Microdischarges are visible after about 1 min. At the beginning microdischarges are smaller with a light yellow color but grow in size and turn orange at later stages. The size of microdischarges becomes larger with increasing time of PEO. The population of small microdischarges decreases during PEO. On the other hand, large microdischarges become noticeable with extended PEO time, after 10 min have passed.

Figure 2 is the surface morphologies of the coatings prepared in different regimes for different time. It is clearly seen that the coatings had quite different surface morphologies at different times. When the time of PEO was $2 \mathrm{~min}$ and $10 \mathrm{~min}$, the deposit on the samples' surface had disappeared and was replaced with microporosity with diameter of about 1 to $2 \mathrm{~mm}$. At $60 \mathrm{~min}$, big spurting holes (diameter of about 4 to $5 \mu \mathrm{m}$ ) a ppeared on the surface and generated big molten particles around the holes.
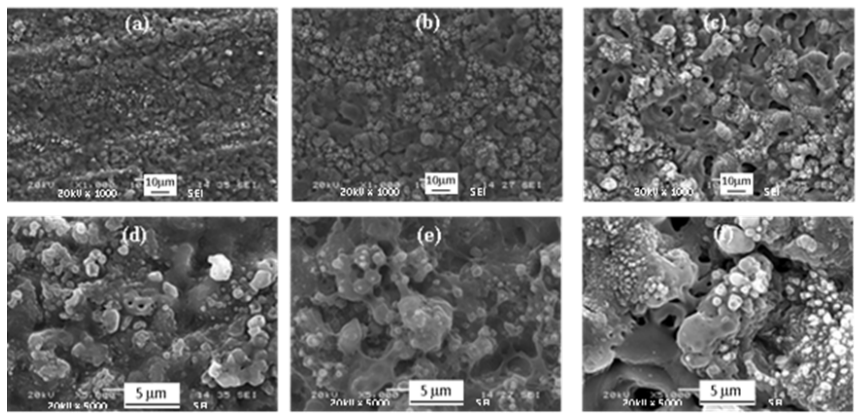

Fig. 2. Surface morphologies of the coatings, (a), (b), (c) PEO coated $(1000 \times)$ for $2 \mathrm{~min}, 10 \mathrm{~min}, 60 \mathrm{~min}$, respectively and (d), (e), (f) $(5000 \times)$ for $2 \mathrm{~min}, 10 \mathrm{~min}$, 60 respectively.
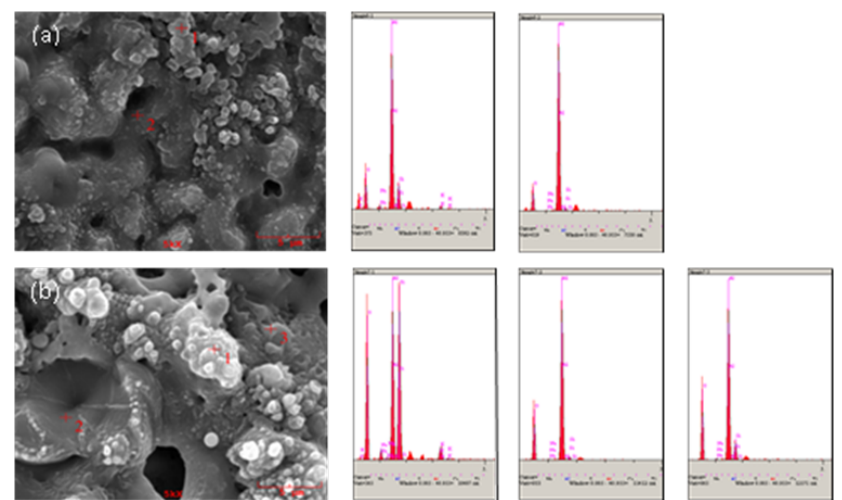

Fig. 3. SEM images and EDS spectra of different PEO process time : (a) $2 \mathrm{~min}$. (b) $60 \mathrm{~min}$.

SEM images and EDS spectra of three regions on coating were shown in Fig. 3. The elements of coating on primary elements are $\mathrm{Al}, \mathrm{Si}$, and $\mathrm{O}$. $\mathrm{Si}, \mathrm{Na}$ and $\mathrm{K}$ come from electrolytic solution. When the PEO process time increases the elements contents was also found to increase
(Fig. 3b). The nodular structure is rich in Si suggesting that it is formed by the deposition of silicon in the solution.

The coating layer was investigated on cross sectional images using SEM for all coated aluminum samples. The thickness of coatings prepared for different time periods is shown in Fig. 4. It can be seen that the coating thickness reaches $19.6 \mu \mathrm{m}$ after treatment for $60 \mathrm{~min}$. The $\mathrm{Al}$ alloy substrate microhardness was $90 \mathrm{HV}_{0.05}$. After MAO, the coating microhardness was $1770 \mathrm{HV}_{0.05}$. The microhardness was mainly dependent on the structure and phase composition. It shows that $\mathrm{PEO}$ process increased the surface microhardness of substrate significantly.

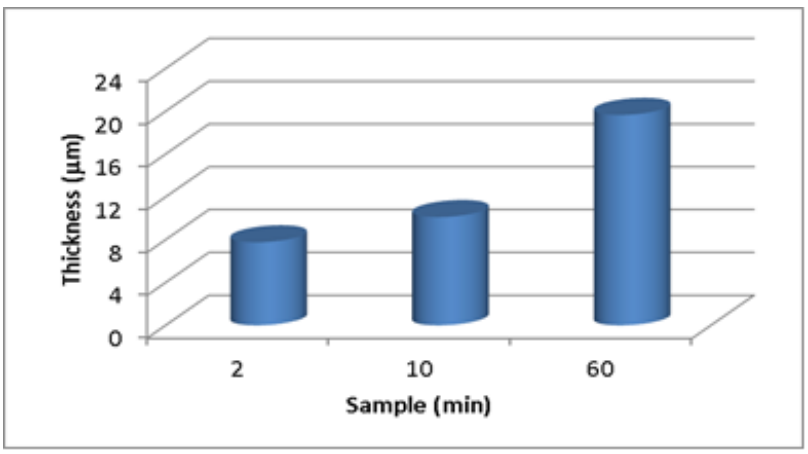

Fig. 4. Thickness of the formed PEO layer in different time.

\section{Conclusions}

The morphology of oxide coatings is strongly dependent on PEO time. It is shown that size of microdischarges becomes larger, while the number of microdischarges is reduced, with increasing time of PEO. In PEO process, the ceramic coating grows inwards towards the alloy substrate (inner layer) and outwards to the coating surface (outer layer) simultaneously. The pore size on the surface of coating layer increases with increasing coating time of EPO. The rates of growth of the outer and inner oxide layers are dependent on the surface parameters. The $\mathrm{PEO}$ films formed on $\mathrm{Al}$ alloy in silicate solution were composed of $\mathrm{O}, \mathrm{Mg}, \mathrm{Al}$ and $\mathrm{Si}$. The thickness of coated layer and hardness is very sensitive to the time, and increases when the coating time increases.

\section{References}

[1] E. Matykina, R. Arrabal, P. Skeldon, G.E. Thompson, Electrochem. Acta 54, 6767 (2009).

[2] M. Montazeri, C. Dehghanian, M. Shokouhfar, A. Baradaran, Applied Surf. Sci. 257, 7268 (2011).

[3] X. Liu, G. Li, Y. Xia, Surf. Coat. Technol. 206, $4462(2012)$.

[4] M. Javidi, H. Fadaee, Applied Surf. Sci. 286, 212 (2013).

[5] K.R. Shin, Y.G. Ko, D.H. Shin, J. Alloys Comp. 509, S478 (2011). 